\title{
Café in a school library: to strengthen links with school and society.
}

\author{
Yuriko Matsuda \\ Kanagawa prefectural Tana senior high school \\ 2-39-2 Katsuradai, Aoba-ku, Yokohama-city, \\ Japan, \\ matuyuri@gmail.com
}

\begin{abstract}
Café in a school library: to strengthen links with school and society A collaborative initiative between school librarian, professional consultant, Principal, teachers and local community in a public high school aims to support students who are low-achieving or belong to low-income families in Japan by setting up a café inside the library. The importance of a cafe in school libraries are revealed from the three point of views; Ibasho, Youth support and Information literacy education. 1) Piccari Café is a value for students not only to add the choices of ibasyo in school but also to let them know about ibasyo outside school. 2 ) Piccari Café works as a platform for each three levels of prevention interventions: universal, selective, and indicated. 3 ) Piccari Café potentially provides students information literacy education without teaching. This case revealed that school library with a meeting, learning and creative function has the potential to generate a platform for students to strengthen links with school and society.
\end{abstract}

Keywords: school library, café, proactive consulting, youth support

\section{Introduction}

On December 11th 2014, Piccari Café, named after Piccari library, has opened at Kanagawa prefectural Tana senior high school in Yokohama. The cafe basically opens every Thursday's lunch time and after school in the library, where soft drinks and snacks are provided for free. Management is carried by NPO PANORAMA and the operating funds are covered with a 
contribution including Crowd funding and grant in aid. Piccari Café is pretty popular among students. Sometimes, more than 200 students come in a day (see Figure1). In the school year 2015 , the cafe was opened 39 times and a total of 5,220 students came.

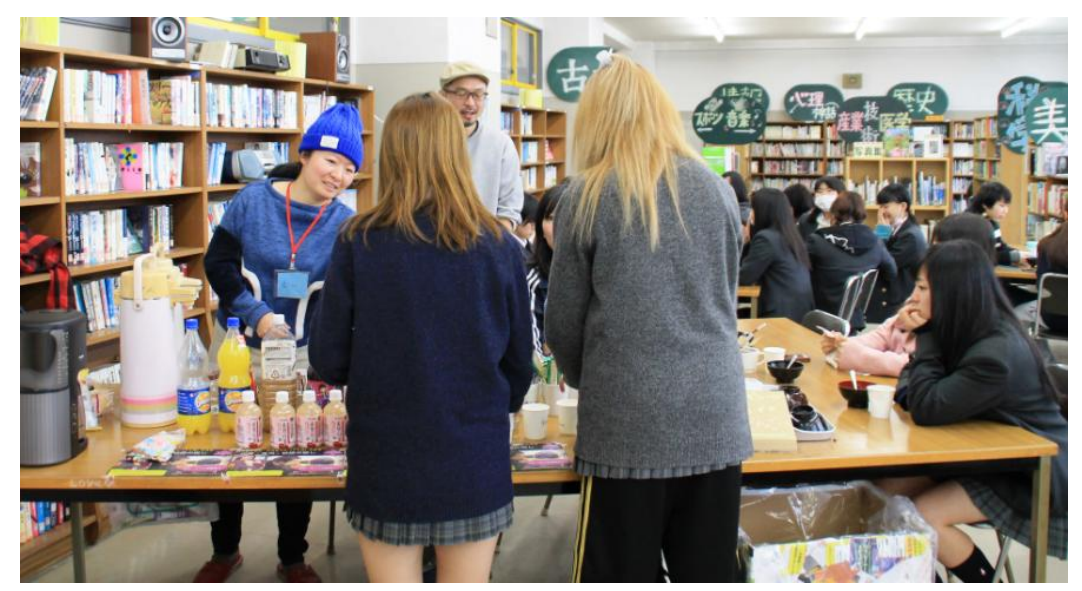

Figure 1: Piccari Café

Kanagawa prefectural Tana senior high school, established in 1978 and located in suburb of northern Yokohama was designated as "Creative School" by the prefectural Board of Education in 2009. "Creative School" is a school which is given a mission to support students, who have low academic skills with various difficult backgrounds, for them to acquire knowledge and skills required for independent living.

The school has promoted various mechanisms in supporting students such as small group learning classes for English and mathematics, the job assistance center and making the school into ibasyo (one's own place) for all students. Those efforts are made possible through the interactive relationships between teachers and students, among teachers and with the help of people in the community.

The method of selection is based on the status of students in junior high school and through a presentation and there's no achievement test. As a result, the number of students who have learning problems is increasing year by year. There are various factors that affect the low academic skills of students. These are poor economic status, bad family condition, refusal to go to school, developmental disability, learning disability or being a newcomer. These are complicated in many cases. 
Therefore, multilayered and utmost support systems not only for students' learning but also for their everyday life to their career after graduation have been created with collaboration between school staff and outside resources. The definite fruit is becoming an apparent in increasing graduation rate that is to decrease rate of student drop out (see Figure2). And it is to reduce the number of students who are undecided of their career after graduation (see Figure3).

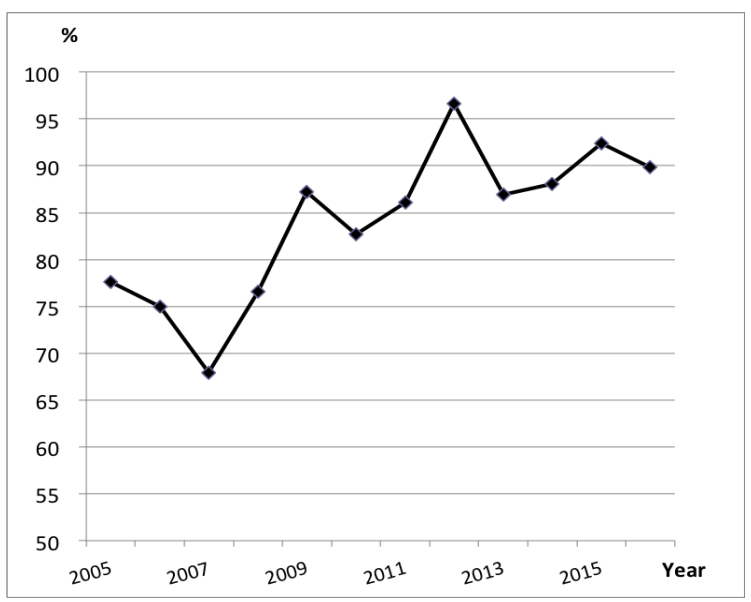

Figure2: Changes in the graduation rate

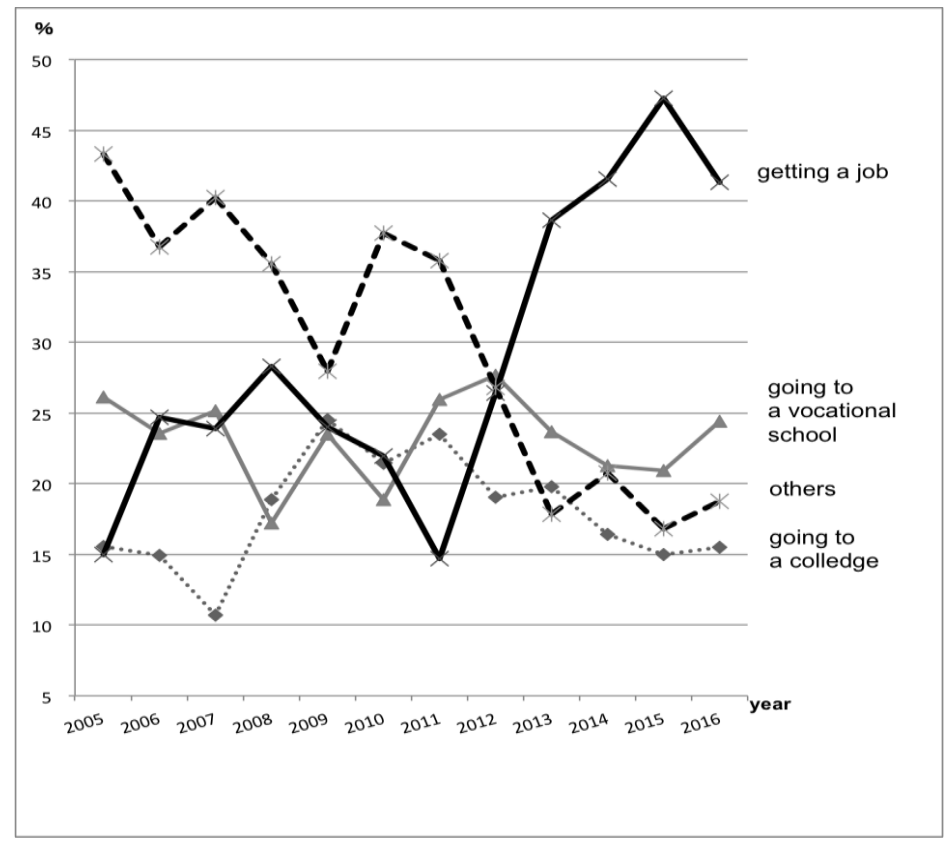

Figure3: Career decision of the students 
Nevertheless as with this kind of school, support for the students who don't express about their problems tend to be delayed. A way to cover that point is "proactive consulting in a communal space" which is a new approach of consulting for youth started in June of 2011 in Piccari library. As in a communal and relaxing atmosphere, students are able to meet with the consultants naturally and eventually their subconscious needs or potential problems are discovered early to prevent them from dropping out of school and become self-reliant.

Table 1: The difference between personal consulting and proactive consulting

\begin{tabular}{|l|c|c|}
\hline & personal consulting & proactive consulting \\
\hline environment & closed & open \\
\hline place & special & common \\
\hline appointment & necessary & not necessary \\
\hline consulter's needs & conscious & conscious / subconscious \\
\hline consulter's chief complaint & generally clear & generally vague \\
\hline
\end{tabular}

In performing proactive consultant, the choice of the place is particularly important. Piccari library was the most qualified place; 1) a free association place where students can gather naturally, 2) a space where consultants can act naturally. And school library was the most appropriate place where a school librarian as a school staff stays. It is necessary for the outside consultants who come only once a week to collaborate with someone who can tell information about students in the daily school lives or develop the relationship between the students and school staff.

Practically, proactive consulting in the library has achieved the desired effect in finding and solving students' problems and referring them to the appropriate consultants and concerned agencies outside the school, if necessary.

The main objective of Piccari Café is to develop proactive consulting approach. The school library was chosen again as the most appropriate space to this effort, because it has been a familiar place for both students and the consultants, where they can encounter various media and people in order to gain more cultural and social inspiration. 
Moreover, the possibility of scheme for supporting students has been extending by café approach. First, it became easier for people outside of the school to participate in school through working as cafe volunteer or making a donation. Therefore, students are able to interact with various people in the library if they want. Consequently, students who have serious problems can be found more easily as well as can have some possibilities to build social relations in the future. Second, it became richer for students to enjoy cultural experiences through various café events.

This paper considers the importance of a cafe in school libraries in this digital age from the three point of views; Ibasho, Youth support and Information literacy education.

\section{Ibasyo and Piccari Café}

Ibasyo is one of the functions of school library in Japan. According to Araya, originally, the term began to be used in relation with educational problems around 1980, when children's refusal to go to school became a social issue in Japan (Araya, 2001). In 1990, the meaning of ibasyo had changed from just a physical but psychological place like "kokoro no ibasho (psychological place)" as announced by Ministry of Education, and to be recognized that ibasyo is needed by not only some but all children. Within the context of history, ibasyo became recognized as an essential function of a school library.

Many Students come and spend their time in the Piccari library every lunch time or after school asking about different relationships in classrooms. Quite a lot of students spend their time in the library until closing time, who want to kill time before going to their part-time job as a supplement for their family income. Others just don't want to go home for some reason. From here, it is necessary to consider that ibasyo function of Piccari Cafe and that of Piccari library are both important for students. Students' experiences in special ibasyo and daily ibasyo are both influence them. The information about the students that are shared with the school and cafe staffs allow us to discover more about the students. These pieces of information enable us to support them.

Tana Senior High School is unique and special because it has policies that make the school into an ibasyo for the students. With the existing set-up, these school policies are almost materialize to its ideal form. There is no need for the school infirmary and school library to be 
converted into an ibasyo because the school itself is a safe place for the students. Important thing for the students is to be able to choose the place they feel accepted.

Piccari Café is an added school facility that allows the student to interact with other individuals outside school. In this place, they could meet youth support specialists, community ibasyo managers, and related individuals that could be of help to them. The presence of cafe in the campus is a value not only to add the choices of ibasyo in school but also to let students know about ibasyo outside school.

\section{Preventive supports and Piccari Café}

Araki \& Nakazawa describe the types of students that were provided with preventive supports, as shown in the IOM model (National Institute of Mental Health, 2001), into three categories based on level of risk: universal, selective, and indicated (Araki \& Nakazawa, 2009). The universal prevention is for all students that belong to the school. The mission of universal prevention is to prevent the problem by providing all students with the necessary information and skills. The selective and indicated prevention is for the students that teachers are concerned. The mission of selective prevention is finding a solution to the problem by detecting the problem early. Indicated interventions target students who are already in high-risk situation. The mission of indicated prevention is to solve the problem.

\section{The universal prevention of Piccari Café}

There are some efforts being applied to the universal prevention in Piccari Café.

The first one is that students simply come to the library just for the café in the beginning. To learn such a cultural behavior pattern help themselves in the future. Students who are low-achieving or belong to low-income families have less custom to read books. They don't have a behavior pattern to fill their minds with knowledge or to consult books when they are in trouble. Piccari Café is effective in strengthening students' cultural capital for their future.

The second one is to strengthen students' human resources by encountering good adults naturally in the cafe. One of the true nature of the problem of poverty is social isolation, which is the situation of getting into another trouble due to the lack of help or the lack of idea of getting help. And one of the true nature of youth problem is also isolation from the other generation. In Piccari Café, students and adults have a good time together. And it is noteworthy that 
graduates also come to Piccari Café as volunteers. For students, graduates are familiar role models. For graduates, the cafe is the place to see familiar teachers and to meet other good adults in the community. Piccari Café is effective in strengthening students' human resources.

The third one is to have a chance to gain knowledge that is useful for the future. Piccari Café staff organizes various events such as a talk about marriage, pregnancy and childbirth. Girls belonging to low-income families tend to get pregnant in adolescence and are in a danger of not being able to graduate or get a job.

The forth one is to make stage for each students in Piccari Café. For example, Japanese tea ceremony club students held tea ceremony and a student who is good at drawing made welcome posters for visitors from abroad, students who are good at singing held a concert and a student who is a kendama toy expert taught beginners how to play (see Figure4). Such opportunity to develop students' Self-Esteem is a prevention function needed by all the school.

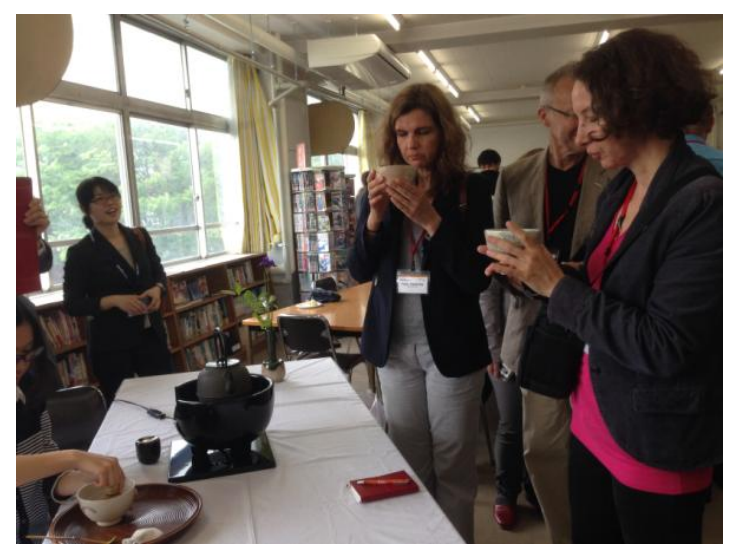

Figure 4: Students held tea ceremony for visitors from abroad

\section{The selective prevention of Piccari Café}

The selective prevention is the most effective effort of Piccari Café to help students with their problems they don't usually talk about. Teenagers generally think they cannot or should not talk their problems to professional supporters or consultants, even though their problems are very serious ones. It is important for consultants to start meeting with students first, then build a genuine rapport with them. In communal and relaxing atmosphere of Piccari Café, students chat with adults who are not teachers or their family member, and talk about themselves little 
by little. Through the communication, adults in the cafe interpret the sense of incongruity or non-verbal cues.

This approach of proactive consulting is proven to be valuable. Before the cafe started, proactive consultant had already held in the Piccari library. According to Suzuki et.al, from April 2012 to March 2013, proactive consulting sessions by two professional consultants held 312 times in total and personal consulting sessions held by the same consultants 131 times in total (Suzuki et.al, 2013). 44 students got the personal consulting sessions, and 7 out of these were from the proactive consulting sessions. Students who have serious problems were 22 out of the 44 , and 5 students out of these were from proactive consulting sessions. Without proactive consulting, we would not be able to determine the problem of those 5 students.

With added various supporters, Piccari Café is more effective in detection of students' problem.

\section{The indicated prevention of Piccari Café}

In April 2016. new effort named "DROP-IN" began, which NPO PANORAMA provides personal consultations by two professional consultants in a private room of Tana high school every two weeks. The target is the students and the graduates in the level of Indicated interventions. This effort has started off on a good note with constant stream of appointments. One of the consultants of DROP-IN and the chief manager of Piccari Café is the same person. It is easy to understand that students come to talk to the person who is familiar and worthy of their faith and trust.

Piccari Café is also a kind of platform to share information about students as much as possible not only among the supporters for youth of NPO PANORAMA, a school librarian and the teachers in charge of the effort but also among the related staffs such as nursing teachers, a school counselor, a school social worker, a career counselor and administrators.

Furthermore, there is a compelling need for every school library staff to create a mechanism to connect to solve the students' problems that are found in the library.

According to Matsudo, many librarians felt there are problems and difficulties in supporting children with special educational needs. And attendance at the school staff training, 
consultation sessions and collaboration with the school nurse and school counselor who doesn't evaluate students based on their abilities relieved the issues of hesitation and anxiety (Matsudo, 2006).

In many cases, the only thing school librarians can do is to listen to children. The problem is that there is no mechanism to connect to the next support after finding children's difficulties. Piccari library works and serves as a solution of this problem. The time to share information about students among school librarian, cafe staff including consultants and teachers after closing the cafe is the key feature of the Piccari Café project.

Consequently, Piccari Café reveals school librarians' new role: 1) To develop a good relationship between students and consultants, 2) To develop a good relationship between consultants and teachers.

Generally, what people think of " making school a platform for prevention" is a platform for the Indicated prevention interventions. While Piccari Café works as a platform for each three prevention interventions: universal, selective, and indicated.

\section{Information literacy education and Piccari Café}

The various ways to support the students' learning has remarkably increased with the addition of cafe function. Both analog media, such as books, magazines, newspapers, and digital media that includes internet and even people, such as school librarian, teachers and students are all essential components of the school library. The students encounter information through these media intentionally or accidentally by simply stepping into the school library. Posters, comfortable sofas and tables that are diagonally arranged are also considered as media. The availability of these different media generated a "cultural shower" environment.

The cafe has made the cultural shower become richer and wider. Because the availability of food and drinks, music songs, youth supporters, volunteers, visitors, reporters and a sign of empathy from people outside donating food and drinks are added. It became much easier to hold various kinds of events like musical performance, cookie icing class or Christmas party.

It is also highly significant to shower the students with cultural shower from perspective of information literacy education. The widely used definition of "information literacy" is a set of abilities "to recognize when information is needed and have the ability to locate, evaluate and 
use effectively the needed information" (American Library Association, 1989). Nozue expresses the definition in other words as "a problem-solving tool in community" and defines "information literacy education" as "a tool to learn how to solve a problem" (Nozue, 2014). And he insists that it becomes more important to consider information literacy education without teaching after ten years of development and utilization of various tools for teaching information literacy. Thus, it is important to consider the creation of an environment which promotes the growth of students' information in a natural way. This is one of the ways of information literacy education.

The students' involvement in Piccari Café is an opportunity for them to resolve their vague sense of anxieties to manageable definite issues. This is possible because they can connect to individuals that could help them solve their problems. If we can call this information literary education, then information literacy education in school libraries can potentially be extended.

\section{Conclusion}

As noted in the introduction, the project of a cafe in a school library was planned in the effort of supporting students through proactive consulting. After a year of this practice, it became clear that the possibility of scheme for supporting students has been extending by café approach, besides that the proactive consulting has achieved the desired effect in finding and solving students' problems. First, students are able to interact with various people in the library if they want. Second, it became richer for students to enjoy cultural experiences. Consequently, not only students who have serious problems but also all the students can have some possibilities to build social relations in the future.

The importance of a cafe in school libraries are revealed from the three point of views; Ibasho, Youth support and Information literacy education.

1 ) Piccari Café is a value for students not only to add the choices of ibasyo in school but also to let them know about ibasyo outside school.

2 ) Piccari Café works as a platform for each three levels of prevention interventions: universal, selective, and indicated.

3 ) Piccari Café potentially provides students information literacy education without teaching. 
Furthermore, Piccari Café creates a mechanism to solve the students' problems that are found in the library. This reveals school librarians' new role: 1) To develop a good relationship between students and consultants, 2) To develop a good relationship between consultants and teachers.

This collaborative initiative between school librarian, professional consultant, Principal, teachers and local community revealed that school library with a meeting, learning and creative function has the potential to generate a platform for students to strengthen links with school and society.

\section{References}

Araki, Fumiyo \& Nakazawa, Jun (2009). The roles of teachers and school counselors in school-based prevention: Through interviewing with teachers. Bulletin of the Faculty of Education, Chiba University 57, 125-136.

Araya, Shuhei (2001). The Commitment and Relationship of Teenagers in the 'Ibasho'-type Facilities : The Ethnography of the Public Facilities for Junior and Senior High School Students, 'Yu-Suginami'. Studies in Lifelong Learning and Adult Education, 26, 21-30.

Matsudo, Hiroyo (2006). School Librarians' Views on Aiding Children with Special Educational Needs in the School Library. Journal of Japan Society of Library and Information Science. 52 (4), 222-243.

National Institute of Mental Health (2001). Priorities for prevention research at NIMH. Prevention \& Treatment, 4, Article17

Nozue, Toshihiko (2014). Information literacy education in libraries: The past and future. The journal of Information Science and Technology Association. 64(1), 2-7.

Suzuki, Akiko, Matsuda, Yuriko \& Ishii, Masahiro (2014). A Proactive Consulting in Communal Space : A New Approach of School Consulting : A Practical Fieldwork in a School Library 
of a Public High School for Low-Achieving, Low-Income Students in Japan. Studies in Lifelong Learning Infrastructure Management. 38, 1-17.

\section{Biographical note}

Yuriko MATSUDA has worked as School Librarian at public senior high school in Kanagawa prefecture, Japan since 1983; her main professional topic focuses on how school library can provide various kinds of learning opportunity for students collaborating with teachers, president and people outside of the school. She also has worked as Part-time lecturer at Hosei university in Tokyo since 2008 and worked as Director of NPO PANORAMA since 2014. 